\title{
Avaliação clínica e bioquímica de cães submetidos a dois métodos de hidroterapia
}

[Clinical and biochemical evaluation of dogs submitted to two methods of hydrotherapy]

\author{
A.S. Belfort ${ }^{1}$, P.F.N.S. Malavazi ${ }^{2}$, C. Pelizzari ${ }^{2}$, L.M. Laskoski ${ }^{2}$, A.D. Pacheco ${ }^{2}$, \\ R.S. Oliveira ${ }^{2}$, M.M.P. Fernandes ${ }^{3}$, M.S. Santos ${ }^{1}$, S.F. Souza ${ }^{2} *$ \\ ${ }^{1}$ Médica veterinária autônoma, Rio Branco, AC \\ ${ }^{2}$ Universidade Federal do Acre - Rio Branco, AC \\ ${ }^{3}$ Aluna de pós-graduação - Universidade Federal do Acre - Rio Branco, AC
}

\begin{abstract}
RESUMO
Avaliou-se a resposta dos parâmetros fisiológicos de frequência cardíaca (FC) e respiratória (FR), temperatura retal (TR) e a atividade sérica das enzimas creatina quinase (CK) e lactato desidrogenase (LDH) em cães adultos hígidos, machos e fêmeas, sob duas modalidades de hidroterapia. Dez cães foram distribuídos em dois grupos de cinco animais, denominados de grupo I (caminhada em esteira aquática) e grupo II (natação) e submetidos a duas sessões por semana com duração inicial de 10 minutos, acrescida de cinco minutos por sessão até 30 minutos, durante nove semanas. As avaliações foram realizadas antes, imediatamente depois e quatro horas após o exercício em todas as sessões para as variáveis de FC, FR e TR e nos dias um, sete, 28 e 60 para CK e LDH. Não houve diferença $(\mathrm{P}>0,05)$ quando comparados os valores médios dos parâmetros fisiológicos de frequência cardíaca e respiratória e de temperatura retal. Os níveis de CK e LDH não se elevaram após a hidroterapia nos diferentes tempos e dias avaliados. Dessa forma, foi possível concluir que as sessões de natação e de caminhada em esteira aquática não causaram alterações nos parâmetros fisiológicos de frequência cardíaca e respiratória, temperatura retal e nos níveis sanguíneos de creatina quinase (CK) e lactato desidrogenase (LDH) no protocolo proposto.
\end{abstract}

Palavras-chave: natação, esteira aquática, fadiga muscular, canino

\begin{abstract}
The physiological parameters of heart rate $(H R)$, respiratory rate $(R R)$, rectal temperature $(T R)$, and serum activity of creatine kinase $(C K)$ and lactate dehydrogenase $(L D H)$ enzymes were determined in healthy dogs, male and female, under two hydrotherapy modalities. Ten dogs were distributed in two groups of five animals, named Group I (underwater treadmill walk) and Group II (swimming), submitted to two sessions per week with initial duration of 10 minutes, plus 5 minutes per session up to 30 minutes, during 9 weeks. The evaluations were performed before, immediately after and 4 hours after exercise in all sessions for the HR, RR and TR variables and on days one, seven, 28 and 60 for CK and LDH. There was no difference $(P>0.05)$ when comparing the mean values of physiological parameters of heart and respiratory rate and rectal temperature. $C K$ and $L D H$ levels did not rise after hydrotherapy at different times and days evaluated. So, it was possible to conclude that swimming sessions and underwater treadmill walking did not cause alterations in the physiological parameters of heart and respiratory rate, rectal temperature, and the blood levels of creatine kinase $(C K)$ and lactate dehydrogenase $(L D H)$ in the proposed protocol.
\end{abstract}

Keywords: swimming, aquatic treadmill, muscle fatigue, canine

\section{INTRODUÇÃO}

A terapia aquática é um dos métodos terapêuticos mais antigos utilizados para o tratamento de disfunções físicas em humanos. As

Recebido em 4 de maio de 2017

Aceito em 14 de fevereiro de 2018

* Autor para correspondência (corresponding author)

E-mail: soraiasouza@yahoo.com propriedades de assistência e resistência que a água promove favorecem aos profissionais $\mathrm{e}$ pacientes a execução de programas voltados para aumento da amplitude de movimento, exercícios que melhorem a resistência, recrutamento muscular, além de facilitar os treinamentos de 
deambulação e equilíbrio (Candeloro e Caromano, 2007).

Nos últimos 10 anos, houve crescimento considerável na popularidade da hidroterapia em cães nos pequenos e grandes centros do Brasil e em várias partes do mundo (Prins e Cutner, 1999; Saunders, 2007; Nogueira et al., 2010; Wainging et al., 2011; Mendes et al., 2015), sendo empregada com sucesso em pacientes com distúrbios ortopédicos e neurológicos (Molyneux, 2004).

O exercício físico pode induzir modificações nos constituintes bioquímicos do plasma, como a creatina quinase (CK) e a lactato desidrogenase (LDH) (Chanoit et al., 2002; Duncan e Prasse, 2005; Kaneko et al., 2008), o que causa sobrecarga nos músculos e gera ruptura das fibras musculares, levando a maior infiltrado de neutrófilos com subsequente liberação de proteínas celulares para a circulação (Siqueira et al., 2009).

A reabilitação física em cães é diferente da que ocorre em humanos. A sessão precisa ser efetiva, prazerosa e segura para os cães e veterinários. Em estudo realizado por Souza et al. (2011), foi possível verificar que um dos cães submetidos a 20 minutos de caminhada em esteira aquática teve alterações nas enzimas lactato desidrogenase e creatina quinase, compatíveis com fadiga muscular durante a primeira sessão, o que é um fator indesejável.

Não foram encontrados estudos avaliando e comparando as alterações fisiológicas de frequência cardíaca e respiratória, temperatura retal e sobre a existência de fadiga muscular, avaliada pela elevação das enzimas creatina quinase e lactato desidrogenase, entre as modalidades fisioterápicas de caminhada em esteira aquática e natação. Logo, o presente estudo teve o objetivo de avaliar as alterações nas frequências cardíaca e respiratória, na temperatura retal e nos níveis sanguíneos de creatina quinase (CK) e lactato desidrogenase (LDH) em cães submetidos a caminhada em esteira aquática e natação.

\section{MATERIAL E MÉTODOS}

O presente estudo foi realizado na Unidade de Ensino e Pesquisa em Medicina Veterinária da Universidade Federal do Acre, município de Rio
Branco, Acre (latitude: -9.974, longitude: 67.8076 e umidade relativa anual: 83,8). A seleção dos cães foi realizada depois de contato prévio com proprietários de cães. Foram selecionados animais que não apresentaram alterações clínicas detectáveis no exame físico e no hemograma, bem como aqueles que nunca tiveram contato prévio com esteira ou piscina. Utilizaram-se 10 cães (Canis familiaris Linnaeus, 1758), sendo três machos e sete fêmeas, adultos, hígidos, sem raça definida, pesando entre 10 e $20 \mathrm{~kg}$, sedentários e domiciliados. Os proprietários dos cães assinaram termo de autorização para a participação dos animais no estudo, e o trabalho foi aprovado pelo Comitê de Ética no Uso de Animais - Ceua/Ufac, antes de seu início, sob o protocolo de $n^{\circ} 60 / 2015$.

Os cães foram distribuídos aleatoriamente em dois grupos de igual número, conforme o seguinte delineamento: grupo I $(n=5$; submetidos a caminhada em esteira aquática); grupo II ( $n=5$; submetidos a natação). A fim de proporcionar a aclimatação dos cães ao ambiente e à manipulação, os parâmetros de frequência cardíaca, respiratória e de temperatura retal foram aferidos em quatro repetições, sendo duas vezes por semana, durante duas semanas, previamente ao início das sessões, para minimizar os efeitos do estresse.

As sessões de caminhada em esteira aquática e natação foram realizadas duas vezes por semana, em intervalo mínimo de 48 horas, durante nove semanas consecutivas, totalizando 18 sessões. $\mathrm{O}$ tempo inicial foi de 10 minutos, aumentando-se cinco minutos a cada sessão, até que se obtivesse o total de 30 minutos, duração mantida até a última sessão.

Os cães do grupo I foram colocados sobre a esteira aquática (Fig. 1A), e o nível da água ajustado até a região do trocânter maior. Nos animais com sinais de fobia, houve alteração gradual no nível da água, até que se alcançasse a profundidade adequada. A água foi aquecida em temperatura média de $30^{\circ} \mathrm{C}$, e a velocidade de realização do exercício ajustada conforme o condicionamento físico, iniciando com $1,5 \mathrm{~km} / \mathrm{h}$ nas sessões 1,2 e $3 ; 2 \mathrm{~km} / \mathrm{h}$ nas sessões 4,5 e 6 ; $2,5 \mathrm{~km} / \mathrm{h}$ nas sessões 7,8 e 9 ; e, por fim, $3 \mathrm{~km} / \mathrm{h}$ até o término do experimento. 
Os cães do grupo II foram molhados aos poucos antes de serem imersos na piscina $(6,20 \mathrm{~m}$ de comprimento x 3,10m de largura $\mathrm{x} 1,40 \mathrm{~m}$ de profundidade) com a água em temperatura ambiente. Todo o procedimento foi realizado de forma assistida, ou seja, os cães fizeram uso de colete para flutuação e foram apoiados na região ventral do tórax e abdômen, quando necessário (Fig. 1B).

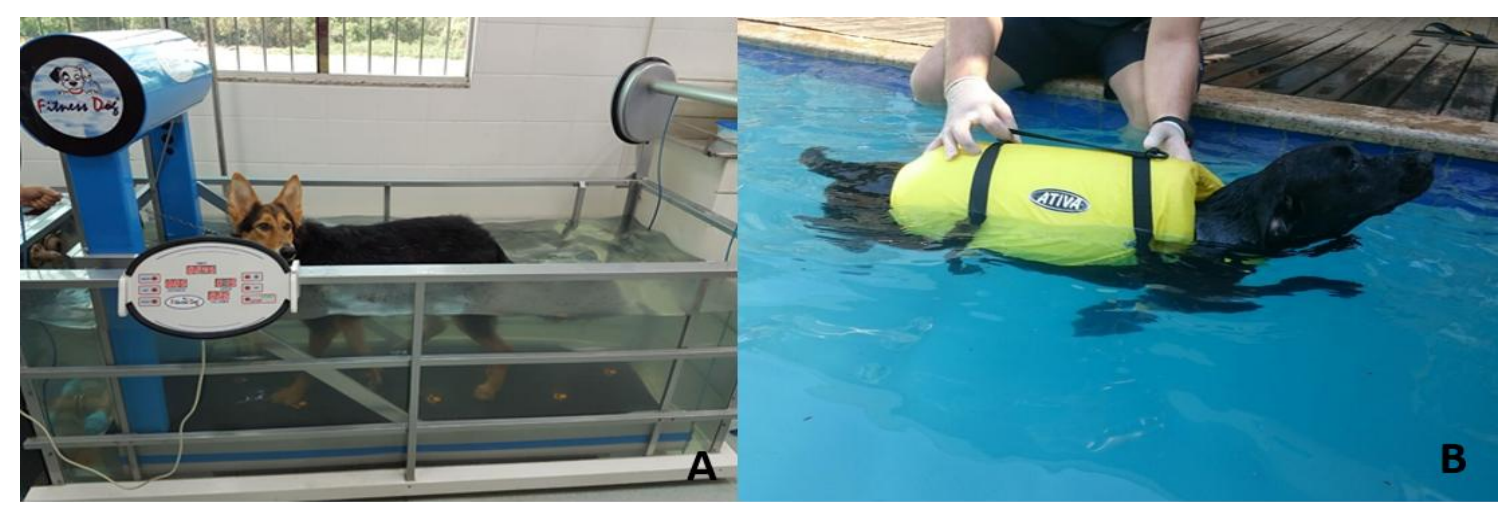

Figura 1. Sessão de hidroterapia em cães, com imersão parcial em esteira aquática (A) e natação (B).

Foram aferidas a frequência cardíaca (FC) em batimentos por minutos (bpm), a frequência respiratória (FR) em movimentos respiratórios por minuto (mpm), com auxílio de estetoscópio e inspeção direta, e a temperatura retal (TR) em graus Celsius $\left({ }^{\circ} \mathrm{C}\right)$, com termômetro digital de ponta flexível Geratherm®. A avaliação clínica foi realizada antes do exercício (T0), imediatamente após (T1) e quatro horas depois das sessões (T2) de caminhada em esteira aquática e natação em todas as sessões. Após a avaliação clínica, os animais foram submetidos a coleta de sangue da veia jugular em três tempos: antes do exercício (T0), trinta minutos depois (T1) e quatro horas após a sessão, nos dias um, sete, 28 e 60.

Realizou-se a coleta de $5 \mathrm{~mL}$ de sangue da veia jugular, que foi acondicionado em tubos sem anticoagulante; depois, estes foram centrifugados em macrocentrífuga a 3200 rotações por minuto, durante cinco minutos. O soro obtido foi armazenado em tubos do tipo Eppendorf®, identificados e congelados a $-20^{\circ} \mathrm{C}$ para posterior análise pelo método cinético em aparelho analisador bioquímico semiautomático, utilizando-se os kits específicos (CK-NAC, Labtest, Brasil, e LDH Labtest, Brasil), seguindo instruções do laboratório de origem.

Para análise estatística, foi realizado o teste de Shapiro-Wilk para avaliação da normalidade; em seguida, foram utilizados os testes de Wilcoxon-
Mann-Whitney para as variáveis frequência cardíaca, creatina quinase $(\mathrm{CK})$ e lactato desidrogenase (LDH). Para as variáveis frequência respiratória e temperatura retal, foi aplicado o teste de ANOVA, com avaliação das médias por Tukey. Todas as análises consideraram $\mathrm{P}<0,05$.

\section{RESULTADOS E DISCUSSÃO}

Durante as duas semanas de adaptação, a média da frequência cardíaca para os animais do grupo I foi de $128 \pm 17,02 \mathrm{bpm}, 98 \pm 49,79 \mathrm{mpm}$ para frequência respiratória e temperatura retal de $38,9 \pm 0,47^{\circ} \mathrm{C}$. Já os animais do grupo II apresentaram média de frequência cardíaca de $120 \pm 22,79 \mathrm{bpm}, 107 \pm 40 \mathrm{mpm}$ para frequência respiratória e temperatura retal de $38,9 \pm 0,33^{\circ} \mathrm{C}$, parâmetros esses que se mantiveram dentro dos intervalos propostos por Feitosa (2014) para cães adultos em repouso, com exceção da frequência respiratória, que superou o intervalo proposto. Isso pode ser explicado pelas elevadas temperaturas e umidade, características da região amazônica (Nobre et al., 2010), bem como pelo mecanismo de termorregulação dos cães, que, mesmo em repouso, apresentaram-se ofegantes, a fim de controlar a temperatura corporal pela troca de calor por meio da evaporação da respiração, promovendo o aumento da frequência respiratória (Cunnhingham, 2014).

$\mathrm{Na}$ primeira sessão de caminhada em esteira aquática, dois animais do grupo apresentaram 
relutância para caminhar; nestes, foi necessária a alteração gradual do nível da água, a fím de evitar estresse e promover melhor adaptação. Após a segunda sessão, quatro animais do grupo apresentavam ambientalização à esteira, realizando a caminhada com facilidade, à exceção de um animal, que caminhou com facilidade somente após a oitava sessão, fato que pode ser explicado pelo temperamento medroso dele. Um cão do grupo que apresentava aversão ao uso de guia em terra, ao realizar a primeira sessão, passou a permitir o uso dela em caminhada terrestre.

Ao serem molhados previamente à imersão para natação, os cães demonstraram reação de fuga já esperada devido à falta de contato prévio com a piscina, mas, após alguns minutos, foram se adaptando ao meio, não sendo necessária a interrupção das sessões em nenhum momento.

Este estudo não mostrou diferença $(\mathrm{P}>0,05)$ quando comparados os valores médios dos parâmetros fisiológicos (FC, FR e TR) entre o grupo de cães submetidos a caminhada em esteira aquática e o grupo submetido a natação em piscina nos diferentes tempos de avaliação (T0, T1 e T2), bem como no decorrer das 18 sessões.

As médias de frequência cardíaca, em ambos os grupos, nos momentos T0 e T2, antes e quatro horas após o exercício, respectivamente, mantiveram-se dentro do intervalo de referência proposto por Feitosa (2014) para cães adultos em repouso. O grupo I apresentou valores acima do intervalo proposto em seis sessões nas aferições do momento $\mathrm{T} 1$, realizadas imediatamente após o exercício (Fig. 2A). Já o grupo II apresentou valores acima do intervalo proposto em oito sessões nas aferições no mesmo momento (Fig. 2B). Os exercícios de natação são mais extenuantes quando comparados aos realizados em esteira aquática, porém os animais do grupo I apresentavam porte físico menor que os do grupo II, o que pode justificar a elevação em alguns momentos. Foi possível verificar que os animais de ambos os grupos apresentaram elevação no parâmetro de FC na quinta sessão, o que coincide com a primeira sessão com duração de 30 minutos.

Em ambos os grupos, após a realização do exercício (T1), houve aumento na frequência cardíaca, porém sem significância estatística, confirmando os resultados obtidos por Coelho (2007), que, ao comparar dois grupos de cães submetidos a teste físico em esteira terrestre, constatou que, após o treinamento de 11 a 14,39 minutos, a FC obteve aumento linear. Piccione et al. (2012) também relataram aumento de FC em cães após exercícios intercalados de caminhada e trote. Sneddon et al. (1989), ao submeterem cães a 30 minutos de exercícios em esteira terrestre, obtiveram média de $138 \pm 16$ na terceira semana de execução. No presente estudo, tanto o grupo submetido a caminhada em esteira aquática quanto o grupo submetido a natação obtiveram média de 159,8 \pm 12 quando submetidos a 30 minutos de exercício em água.

Apesar de não apresentar diferença estatística, foi possível observar que, no momento $\mathrm{T} 1$, logo após o exercício, o grupo II apresentou valores médios de frequência cardíaca maiores em mais sessões quando comparado ao grupo I. Esse fato pode ser explicado pela temperatura da água da piscina, mantida em temperatura ambiente, entre $24^{\circ}$ e $26^{\circ} \mathrm{C}$ (Nobre et al., 2010). Em um estudo realizado em cães de pequeno porte, houve interferência da temperatura da água, a qual provocou alterações fisiológicas durante exercícios aquáticos. Esses animais demonstraram frequências cardíacas maiores durante a natação em água a $25^{\circ} \mathrm{C}$ quando comparados ao mesmo exercício em água a $33^{\circ} \mathrm{C}$ (Nganvongpanit et al., 2014).

Esse aumento também pode ser explicado pela carga de trabalho cardiovascular em cães que não tiveram treinamento prévio, além de exercícios em água serem considerados mais extenuantes em razão de a viscosidade da água promover maior resistência aos movimentos (Rovira et al., 2008; Souza et al., 2011).

Com relação às médias das frequências cardíacas quatro horas após o exercício, observou-se diminuição da FC quando esse período foi comparado ao momento T0, antes do exercício, quando, em ambos os tempos, os animais estavam em repouso, confirmando resultados encontrados por Wyatt e Mitchell (1974), que observaram diminuição significativa da frequência cardíaca de repouso após uma hora do treinamento com cães em esteira terrestre durante 30 minutos. 


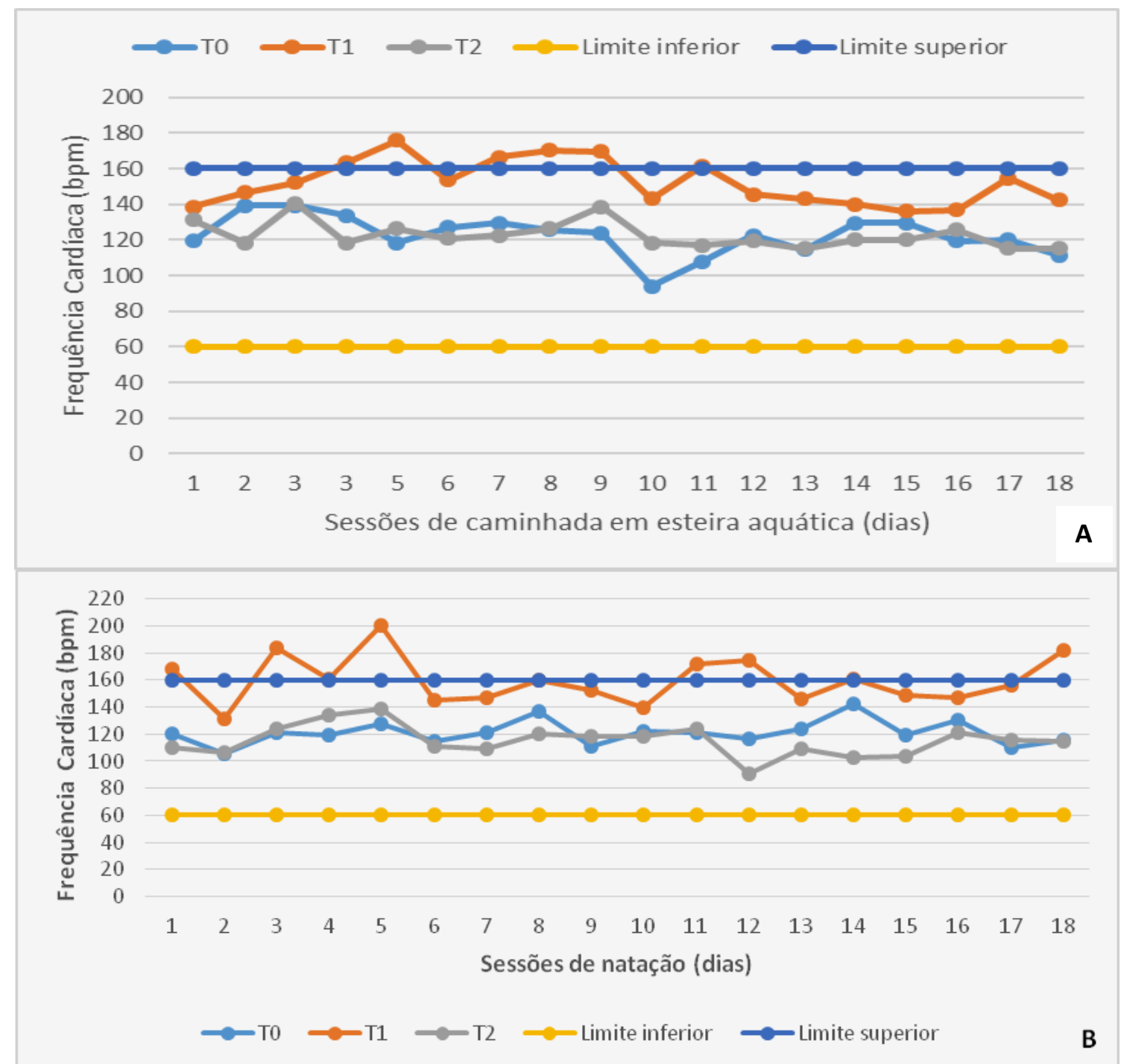

Figura 2. Valores médios da frequência cardíaca de cães submetidos a caminhada em esteira aquática (A) e natação (B), antes (T0), imediatamente depois (T1) e quatro horas após o exercício (T2), no decorrer de 18 sessões. Intervalo de referência para cães adultos em repouso proposto por Feitosa (2014): 60 a $160 \mathrm{bpm}$.

Observou-se diminuição na frequência respiratória (Fig. 3) no momento T1, logo após o exercício, em ambos os grupos. Esses achados corroboram os resultados encontrados por Nganvongpanit et al. (2014), que relataram a diminuição da FR em cães de raças pequenas submetidos a 20 minutos de natação. Tais resultados são diferentes dos realizados em esteira seca, como no caso de Coelho (2007), que, pelo teste de identidade, não encontrou efeitos de diminuição dos valores de FR em treinamento de cães em esteira ergométrica. Esse fato foi também demonstrado por Rovira et al.
(2008), os quais relataram aumento da FR em cães após 20 minutos de exercício de procura e resgate em terra. Os menores registros de FR, portanto, estão ligados à temperatura da água, que ocasionou menor produção de calor corpóreo, exigindo menor perda de calor por meio da respiração. Outro fator para a redução do ritmo respiratório nos exercícios desenvolvidos na água é a necessidade de maior esforço para expansão da caixa torácica, devido à atuação da pressão hidrostática (Carregaro e Toledo, 2008; Nganvongpanit et al., 2014). 
Em ambos os grupos, no momento T2, quatro horas após o exercício, as referidas frequências voltaram a se aproximar dos valores apresentados em T0, antes do exercício, demonstrando recuperação dos parâmetros fisiológicos de FR. Observou-se que, em ambos os tempos, a FR apresentou-se com valores médios bem acima do intervalo proposto por
Feitosa (2014). Esse aumento pode ser explicado pelas elevadas temperaturas locais (Nobre et al., 2010), principalmente em relação ao grupo II, cujos animais ficavam ao ar livre, e pelo fato de a aferição do momento $\mathrm{T} 2$ ser realizada durante o período vespertino, quando as temperaturas ambientais encontravam-se mais elevadas.
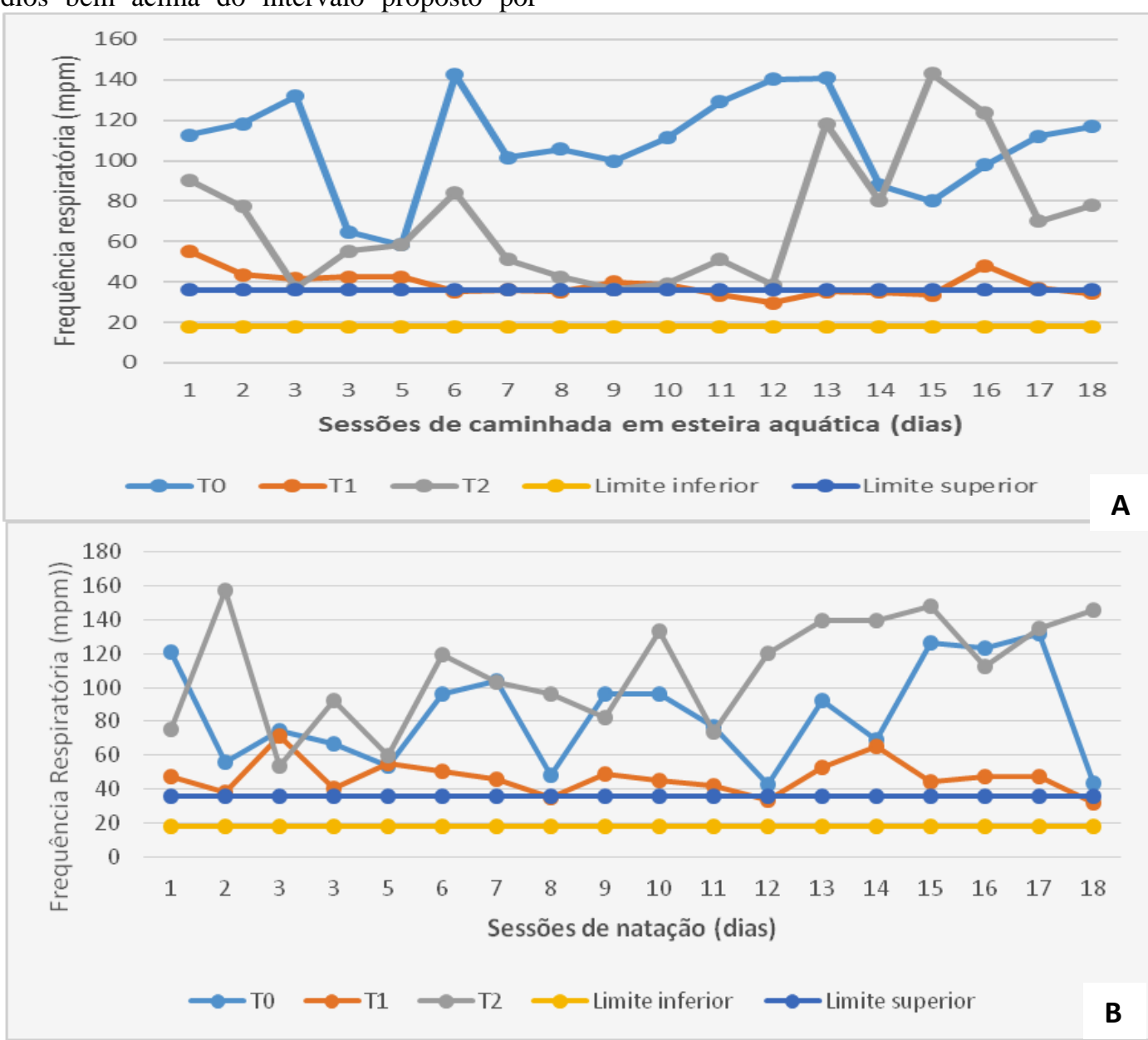

Figura 3. Valores médios da frequência respiratória de cães submetidos a caminhada em esteira aquática (A) e natação (B), antes (T0), imediatamente depois (T1) e quatro horas após o exercício (T2), no decorrer de 18 sessões. Intervalo de referência para cães adultos em repouso proposto por Feitosa (2014): 18 a $36 \mathrm{mpm}$.

No tocante à temperatura retal, verificou-se que as médias se mantiveram constantes na maioria das sessões e dentro do intervalo proposto por Feitosa (2014) (Fig. 4A e B).

Observou-se, em ambos os grupos, discreta redução nas avaliações do momento T1. Esse fato se explica pela possibilidade de troca de calor entre os animais e a água, diferentemente do que acontece em outros tipos de exercício fora da água (Toll e Reynolds, 2000). Rovira et al. (2008) perceberam que cães apresentaram média de 40,64 $\pm 0,46$ de TR após serem submetidos por 20 minutos a exercícios de procura e resgate em terra, contrastando com o presente estudo, que encontrou média de 37,98 $\pm 0,47$ após serem submetidos a 30 minutos de caminhada em esteira aquática e $37,88 \pm 0,27$ ao realizarem 30 minutos de natação. 


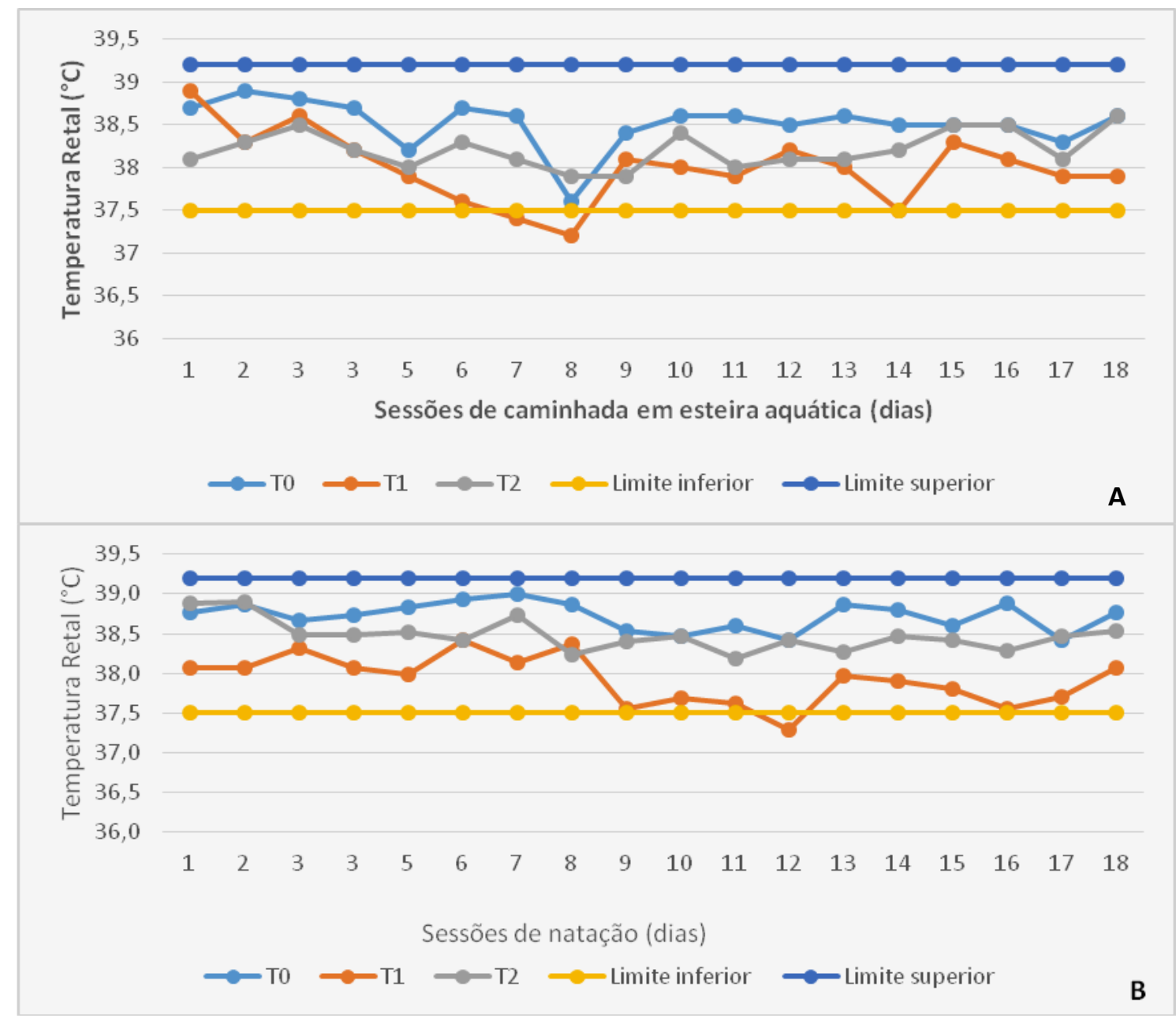

Figura 4.Valores médios da temperatura retal de cinco cães submetidos a caminhada em esteira aquática (A) e natação em piscina (B), antes (T0), imediatamente depois (T1) e quatro horas após o exercício (T2), no decorrer de 18 sessões. Intervalo de referência para cães adultos em repouso proposto por Feitosa (2014): $37,5^{\circ}$ a $39,2^{\circ} \mathrm{C}$.

Quanto à avaliação bioquímica, os valores médios de CK e LDH durante as duas semanas de adaptação foram de 145U/L e 172U/L para o grupo I e de 130U/L e 166U/L para o grupo II, respectivamente.

Os resultados encontrados nos grupos I e II para CK estão demonstrados na Fig. 5. Apesar de os níveis de CK do grupo esteira aquática terem sido inferiores aos encontrados no grupo natação, não foram observadas diferenças $(\mathrm{P}>0,05)$ quando comparados os valores médios de creatina quinase (CK) entre os grupos nos diferentes tempos de avaliação. 


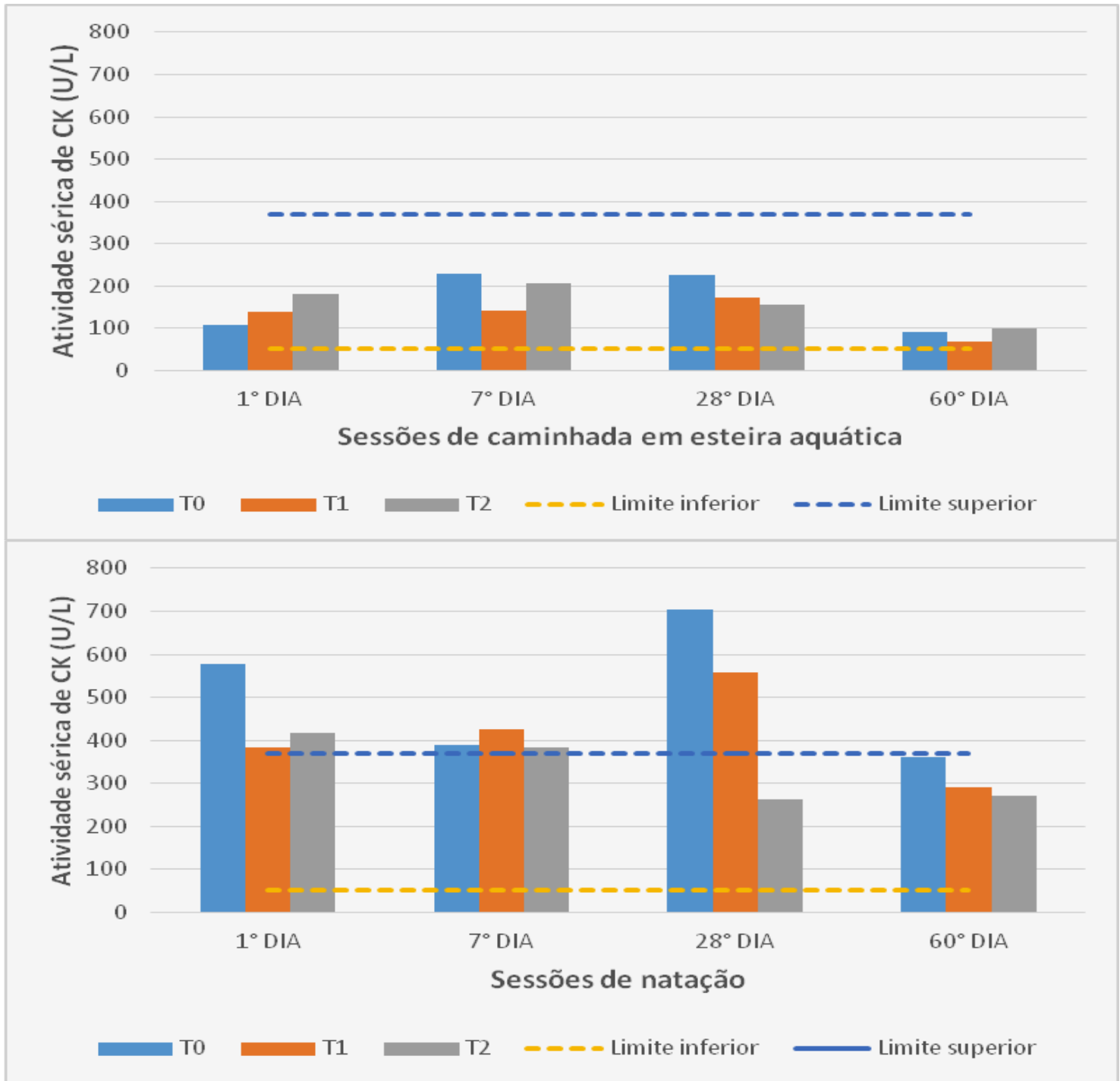

Figura 5. Representação gráfica das médias da atividade sérica de creatina quinase (CK) de cães submetidos a caminhada em esteira aquática (A) e natação em piscina (B), antes do exercício (T0), 30 minutos depois (T1) e quatro horas após o exercício (T2), no decorrer de quatro dias de aferições. Intervalo de referência para cães proposto por Duncan e Prasse (2005): 52 a 368U/L.

Rovira et al. (2008) relataram o aumento de CK (108 \pm 143$)$ após 20 minutos, em cães submetidos a exercícios de procura e resgate, porém não associaram esses achados a fadiga muscular subclínica, visto que os valores pós-exercício retornavam aos níveis apresentados antes do exercício. Segundo Frape (1998), existe uma grande variação individual na atividade sérica dessa enzima e o autor ainda salienta que atividades séricas dessa enzima aumentam ligeiramente após exercícios, não necessariamente sendo indicativas de lesão muscular.
No que se refere às atividades séricas de lactato desidrogenase (LDH) (Fig. 6), houve diferença $(\mathrm{P}<0,05)$ entre T0 e T2 dos grupos na média dos quatro dias de avaliação, com erro-padrão de $\pm 343,1$ para o grupo I e $\pm 78,45$ para o grupo II em $\mathrm{T} 0$, e de $\pm 207,4$ para o grupo I e $\pm 48,42$ para o grupo II em T2. Como os valores elevaram-se apenas antes do exercício, esse fato possivelmente está ligado à presença de hemólise, que, mesmo em pequenos graus, pode causar a elevação da enzima lactato desidrogenase (Gonzáles e Silva, 2006). 


\section{Belfort et al.}

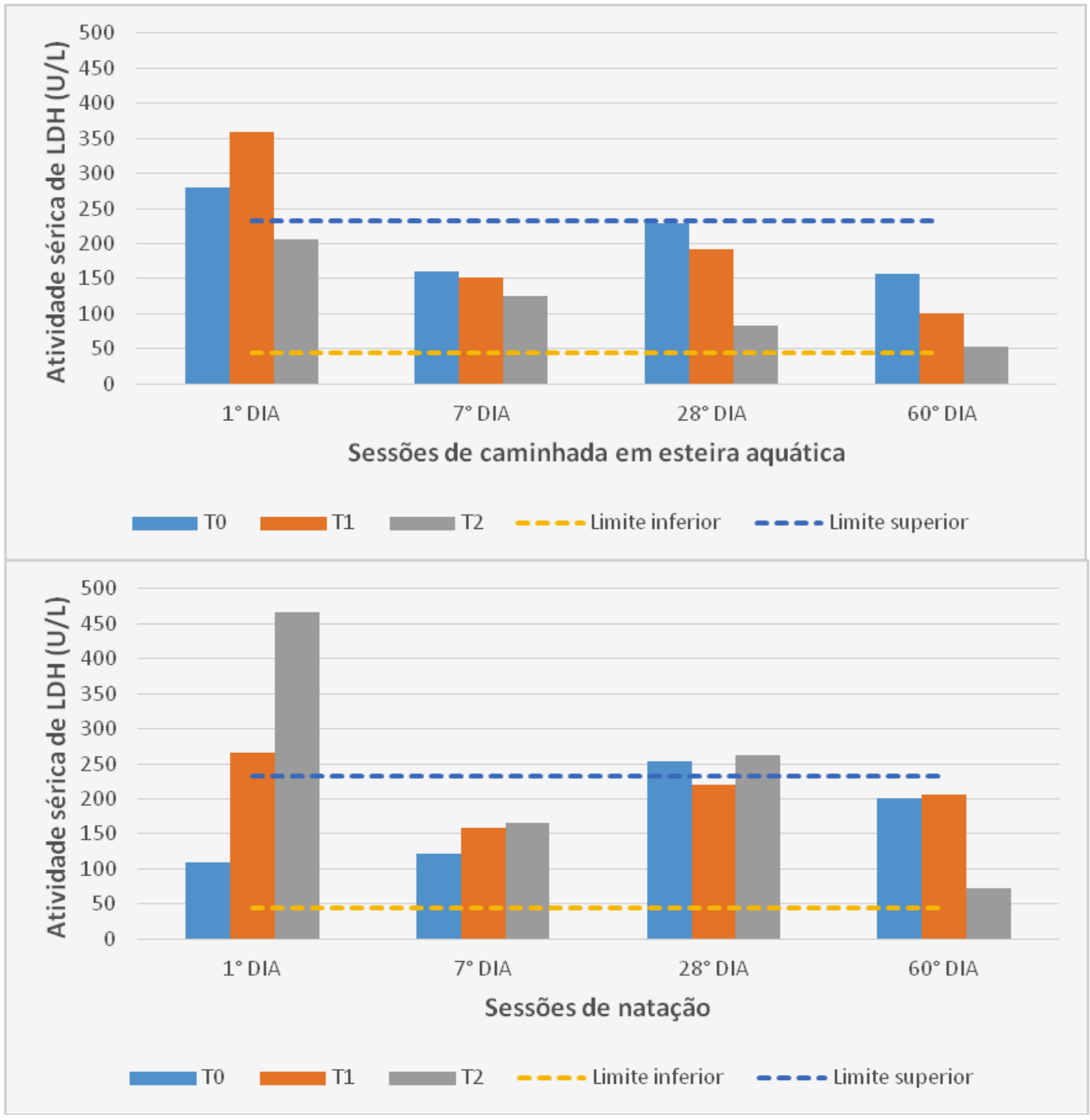

Figura 6. Representação gráfica das médias da atividade sérica de lactato desidrogenase (LDH) de cães submetidos a caminhada em esteira aquática (A) e natação em piscina (B), antes do exercício (T0), 30 minutos depois (T1) e quatro horas após o exercício (T2), nos dias um, sete, 28 e 60 . Intervalo de referência para cães proposto por Kaneko et al. (2008): 45 a 233U/L.

Souza et al. (2011) relataram aumento de níveis séricos de $\mathrm{LDH}$ em um cão submetido a 20 minutos de caminhada em esteira aquática, resultado que pode sugerir a presença de fadiga muscular quando se inicia a sessão com esse tempo. No presente estudo, o início das sessões ocorreu com cinco minutos de atividade, com aumento gradual no tempo até 30 minutos, justificando o fato de não ter havido sinais de fadiga muscular.
Rovira et al. (2008) relataram aumento nos níveis séricos de LDH em cães submetidos a exercícios de procura e resgate, quando os valores aferidos antes dos exercícios normalizaram após 30 minutos de descanso.

Comis (2006), em um estudo que analisava a influência do tempo e da temperatura sobre a estabilidade dos constituintes do soro e plasma sanguíneo de equinos, relacionou ainda que outros fatores podem causar alterações nos 
resultados dos exames, entre eles pode-se citar a idade, a dieta, o método de coleta do material, o armazenamento, a manipulação laboratorial, além das alterações biológicas individuais.

\section{CONCLUSÕES}

Foi possível observar que os cães, quando submetidos a caminhada em esteira aquática e natação no protocolo proposto, não demonstraram alterações nos parâmetros fisiológicos de frequência cardíaca e respiratória, temperatura retal e nos níveis sanguíneos de creatina quinase (CK) e lactato desidrogenase (LDH).

\section{REFERÊNCIAS}

CANDELORO, J.M.; CAROMANO, F.A. Discussão crítica sobre o uso da água como facilitação, resistência ou suporte na hidrocinesioterapia. Acta. Fisiátrica, v.13, p.711, 2007.

CARREGARO, R.L.; TOLEDO, A.M. Efeitos fisiológicos e evidências científicas da eficácia da fisioterapia aquática. Movimenta, v.1, p.2327, 2008.

CHANOIT, G.P.; CONCORDET, D.; LEFEBVRE, H.P. et al. Exercise does not induce major changes in plasma muscle enzymes, creatinine, glucose and total proteins concentrations in untrained Beagle dogs. J. Vet. Med., v.49, p.222-224, 2002.

COELHO, A.S. Parâmetros fisiológicos de cães submetidos a treinamento em esteira. 2007. 23f. Dissertação (Mestrado em Morfofisiologia dos animais domésticos e selvagens) - Universidade Federal de Viçosa, Minas Gerais, Viçosa, MG.

COMIS, M.B. Influência do tempo $e$ temperatura sobre a estabilidade de constituintes do soro e plasma sanguíneos de equinos Mangalarga Marchador. 2006. 111f. Dissertação (Mestrado em Clínica de grandes animais) Universidade Federal de Viçosa, Minas Gerais, Viçosa, MG.

CUNNINGHAM, J.G. Tratado de fisiologia veterinária. 5.ed. Rio de Janeiro: Elsevier, 2014. $624 \mathrm{p}$.

DUNCAN, J.R.; PRASSE, L.W. Patologia clínica veterinária. 4.ed. Barcelona: Multimédica, 2005. 550p.
FEITOSA, F.L.F. Semiologia veterinária: a arte do diagnóstico. 3.ed. São Paulo: Roca, 2014. 640p.

FRAPE, D. Equine nutrition \& feeding. 2.ed. Oxford: Blackwell Science, 1998. 564p.

GONZÁLEZ, F.H.D.; DIAS, S.C. Introdução à bioquímica clínica veterinária. Porto Alegre: UFRGS, 2006. 364p.

GONZÁLEZ, F.H.D.; SILVA, S.C. Patologia clínica veterinária: Texto introdutório. Porto Alegre: Gráfica da UFRGS, 2008. 342 p.

KANEKO, J.J.; HARVEY, J.W.; BRUSS, M.L. Clinical biochemistry of domestic animals. 6.ed. San Diego: Academic Press, 2008. 928p.

MENDES, S.; COUTINHO, I.; REBELO P. Hidroterapia canina. Rev. Port. Ciênc. Vet., v.110, p.160-164, 2015.

MOLYNEUX, J. Hydrotherapy pool - toy or tool? In. Practice, v.25, p.226-228, 2004.

NGANVONGPANIT, K.; BOONCHAI, T.; TAOTHONG, O. et al. Physiological effects of water temperatures in swimming toy breed dogs. Kafkas Univ. Vet. Fak. Deg., v.20, p.177-183, 2014.

NOBRE, C.A.; OBREGÓN, G.O.; MARENGO, J.A. Características do clima Amazônico: aspectos principais. Amazonia Global Change Geophys. Monograph S., v.186, p.149-162, 2010.

NOGUEIRA, J.L.; SILVA, M.V.M.; ARAÚJO, K.P.C. et al. A utilização da hidroterapia como um recurso na fisioterapia veterinária. Rev. Eletron. Med. Vet., v.14, p.1-7, 2010.

PICCIONE, G.; CASELLA, S.; PANZERA, M. et al. Effect of moderate treadmill exercise on some physiological parameters in untrained beagle dogs. Exp. Anim., v.61, p.511-515, 2012.

PRINS, J.; CUTNER, D. Aquatic therapy in the rehabilitation of athletic injuries. Clin. Sports Med., v.18, p.447-461, 1999.

ROVIRA, S.; MUNIZ, A.; BENITO, M. Effect of exercise on physiological, blood and endocrine parameters in search and rescuetrained dogs. Vet. Med., v.53, p.333-346, 2008.

SAUNDERS, D.G. Therapeutic exercise. Clin. Tech. Small. Anim. Pract., v.22, p.155-159, 2007. 


\section{Belfort et al.}

SIQUEIRA, L.O.; MUCCINI, T.; DALL AGNOL, L.H. et al. Análise de parâmetros bioquímicos séricos e urinários em atletas de meia maratona. Arq. Bras. Endocrinol. Metab., v.53, p.844-853, 2009.

SNEDDON, J.C.; MINNAAR, P.P.; GROSSKOPF, J.F.W. et al. Physiological and blood biochemical responses to submaximal treadmill exercise in Canaan dogs before, during and after training. J. S. Afr. Vet. Assoc., v.60, p.87-91, 1989.

SOUZA, S.F.; PADILHA FILHO, J.G.; MARTINS, V.M.V. et al. Aspectos clínicos e concentração sérica da creatina-quinase e lactatodesidrogenase em cães submetidos à fisioterapia após atrofia muscular induzida. Ciênc. Rural, v.41, p.1255-1261, 2011.
TOLL, P.W.; REYNOLDS, A.J. The Canine athlete. 4.ed. Kansas: Mark Morris Associates, 2000.

WAINGING，M.; YOUNG， I.S.; WILLIAMS S.B. Evaluation of the status of canine hydrotherapy in the UK. Vet. Rec., v.168, p.1-4, 2011.

WYATT, H.L.; MITCHELL, J.H. Influences of physical training on the heart of dogs. Circ. Res., v.35, p.883-889, 1974. 